SAE paper 2005-01-2389. Copyright (C) 2005 SAE International. This paper is posted on this site with permission from SAE International, and is for viewing only. Further use or distribution of this paper is not permitted without permission from SAE 


\title{
Sensitivity of Key Parameters to Dynamics of Hydraulic Power Steering Systems
}

\author{
Miao Wang and Nong Zhang \\ University of Technology Sydney, Australia
}

Amit Misra

Tristar Steering and Suspension Australia, Ltd.

\begin{abstract}
A comprehensive mathematical model of a typical hydraulic power rack and pinion steering system is developed, and the dynamic characteristics of the steering system are analyzed. The mechanism, hydraulic supply lines and the rotary spool valve of a hydraulic power steering system are included in the model, and the numerical calculation is conducted to investigate the sensitivities of the key parameters of the steering system. The results show that the profile of the spool valve and the fluctuation of flow rates significantly affect the dynamic characteristics the steering system.
\end{abstract}

\section{INTRODUCTION}

As the front axle load of the vehicle gets higher (due to size and weight of the vehicle), the manual torque required to turn the wheels gets higher. Thus, power assistant systems, including hydraulic power steering and electric power steering, are widely used in modern vehicles to increase the handling performance of vehicles and reduce the input torque on the steering wheel, and hence, driver fatigue. Though facing the challenge from electric power steering in recent years, hydraulic power steering systems are still playing a main role on the market because of their higher assistant force, higher reliability and lower cost.

While a hydraulic power steering system has many advantages, there are quite a few different vibration and noise phenomena [1] existing in such system which is essentially an integration of hydraulic and mechanical components. A number of power steering system models have been developed by various investigators. Ferries and Arbanas [2] construct the system as a feedback control system, and study it in the frequency domain by using control theory. Simplified valve and hydraulic supply line mathematic models are introduced during the investigation on self-excited vibration in steering systems [3]. A mechanism model [4] and a hydraulic hose and pipe model [5] are also used to carry out various research tasks on hydraulic steering systems.

Focusing on the interaction of different components and the transient dynamic responses of the system, a nonlinear mathematical model of hydraulic power steering system is presented in this paper. In the model, mechanical parts of the system are developed as lumped masses interconnected with springs and dampers. By integrating the cylinder, pump and hoses, a hydraulic circuit model is established where these hydraulic parts are constructed as hydraulic impedance elements, and the rotary spool valve, the key part of the system, is modeled as a four-way open centre spool valve.

Based on the mathematic model, numerical analysis is conducted to investigate the sensitivity of the key parameters, such as the nonlinear valve profile and fluctuation of the flow rate, to the dynamics of hydraulic power steering system. The results show that the vibration amplitude of the hydraulic force applied to the piston is affected when the system parameters change, while the amplitude increases dramatically when those parameters are out of certain ranges. The crucial natural frequencies of the system are dependent on some of the system parameters. Therefore, the stability of the system can be improved by modifying these system parameters and consequently changing the dynamic characteristics of the complete system.

\section{HYDRAULIC POWER STEERING SYSTEM MATHEMATICAL MODEL}

The dynamic components of a typical hydraulic power steering system mainly include steering wheel, input shaft, rotary spool valve, rack and pinion, pump, hydraulic cylinder, hydraulic hoses, tie rod linkage, front wheels and tires. During a steering process, the rotational displacement between the sleeve and spool of the rotary spool valve caused by the driver steer input directs the hydraulic force to one side of the piston in the 
hydraulic cylinder. Since the piston is directly connected with the rack, the hydraulic force on the piston helps the driver steer the two front wheels.

A schematic of a power steering system is shown in Figure 1. The integrated hydraulic power steering system model consists of three subsystems, the mechanism, the hydraulic supply line and the rotary spool valve. Different methods and techniques are applied to analyze those subsystems because of their evidently different dynamic characteristics.

\section{MECHANISM SUBSYSTEM}

As shown in Figure 1, the steering column and torsional bar are modeled as the springs and dampers, and the stiffness of pinion meshed with rack and the stiffness of tire rods are taken account of as well. The twist angle of torsional bar controls the spool valve and this is the key connection between mechanism subsystem and valve subsystem. By the steering arms, the lateral forces of tie rods produce the rotational torque and steers two front wheels. In this model, not only the rotational degrees of freedom of the front wheels are introduced but the lateral movements of front wheels are considered. In the model, the hydraulic cylinder is mounted on the vehicle body by spring and damper, therefore the interaction between the steering system and vehicle body is involved. The lateral displacement of the front part of the vehicle body transfers the vibration from hydraulic cylinder to the tires through the left and right front suspensions. A simplified tire model is used, which includes both the torsional and lateral stiffness of the tires.

Besides the stiffness and damping, friction forces also greatly affect the dynamics of the system. The non-linear friction forces in this model include the friction on the steering column, the friction of the kingpins, the friction between pinion and rack, the friction between piston and hydraulic cylinder, and the friction between tires and the ground. In the numerical analysis, the nonlinear friction forces are represented as hyperbolic tangent functions [4] to reduce the "stiffness" of the calculation. Since the steering vibration at parking speed is the main concern at this stage, the aligning torque on the tires which occurs in middle and high vehicle speed is not involved.

A 12 degree of freedoms (DOFs) model represents the mechanism subsystem and it is constructed by free body diagrams and listed in equation (1). In the model, steering wheel, steering column, pinion, two front wheels and two tires have the rotational DOFs $(\theta)$, and rack (with the piston and tie rods), hydraulic cylinder (housing), front vehicle body, two front wheels have linear displacements $(x)$.

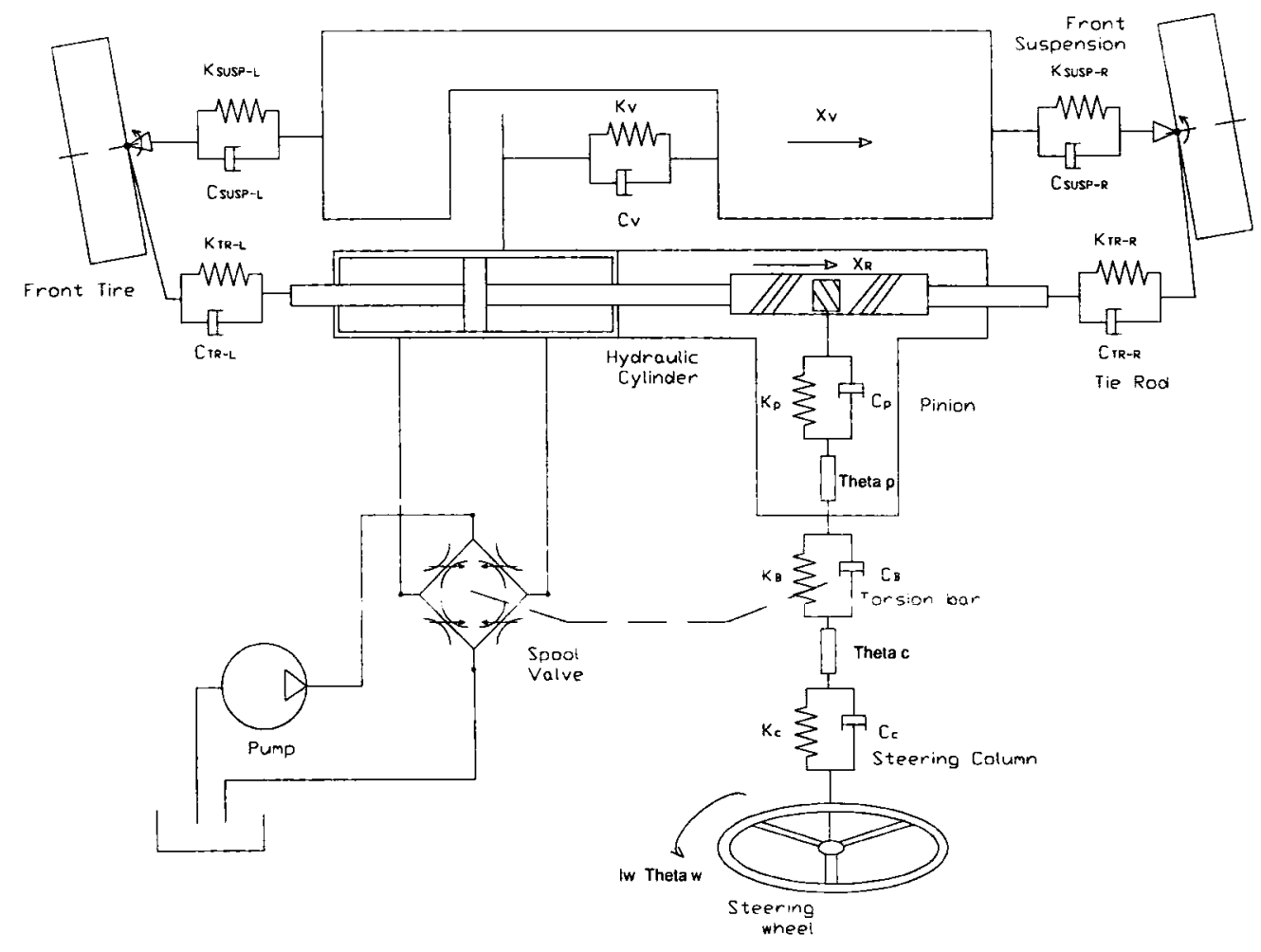

Figure 1: Schematic of steering system model, including the connection with front suspensions 


$$
\begin{aligned}
& {[M(I)]_{2 \times 12}[\ddot{\theta}(\ddot{x})]_{2 \times 1}+[C]_{12 \times 12}[\dot{\theta}(\dot{x})]_{2 \times 1}+[K]_{12 \times 12}[\theta(x)]_{2 \times 1}} \\
& =[T(F)]_{2 \times 1}
\end{aligned}
$$

In the model, mechanical ratios are taken account of, which includes the ratio between pinion and rack, and the ratio between the linear displacement of tie rods and the angular displacement of the steering arms. On the right hand side of equation (1), $T$ and $F$ represent the external torques and forces applied on the elements in the model.

$$
\begin{aligned}
& m_{R} \ddot{x}_{R}-\frac{C_{P}}{N} \dot{\theta}_{P}+\left(\frac{C_{P}}{N^{2}}+C_{T R-L}+C_{T R-R}\right) \dot{x}_{R} \\
& -C_{T R-L} \cdot l \cdot \dot{\theta}_{F W-L}-C_{T R-R} \cdot l \cdot \dot{\theta}_{F W-R} \\
& -\frac{K_{P}}{N} \theta_{P}+\left(\frac{K_{P}}{N^{2}}+K_{T R-L}+K_{T R-R}\right) x_{R} \\
& -K_{T R-L} \cdot l \cdot \theta_{F W-L}-K_{T R-R} \cdot l \cdot \theta_{F W-R}=F_{B}-F_{F R-H}
\end{aligned}
$$

Among the 12 second order coupled differential equations, (2) is the equation for the rack, where $x_{R}$, $\theta_{P}, \theta_{F W-L}$, and $\theta_{F W-R}$ are the DOFs of the rack (with piston and two tie rods), pinion, left and right front wheel. $C_{P}, K_{P}, C_{T R-L}, K_{T R-L}, C_{T R-R}$ and $K_{T R-R}$ are the stiffness and damping of pinion, left and right tie rods. $N$ is the ratio between pinion and rack, $l$ is the distance front the end of tie rod to the center of tire twisting, $F_{F R-H}$ is the friction force between piston and hydraulic cylinder and $F_{B}$ is the hydraulic boost force on piston. In the mechanism model, the boost force is generated by the spool valve model and is the main concern in the steering system vibration study.

\section{HYDRAULIC SUPPLY LINE SUBSYSTEM}

Hydraulic power steering systems comprise a number of tubes and hoses connecting the pump, the valve and the reservoir. The low pressure return line of the steering system does not affect the system much so only the high pressure supply line is considered in this study.

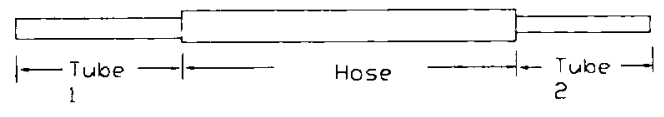

Figure 2: Supply Line

Usually the supply line consists of three elements, a steel tube connecting the pump, a tube connecting the spool valve, and a hose between them which is fabricated from wire braid and synthetic rubber. They are shown as Tube 1, Tube 2 and Hose respectively in Figure 2. The calculations for the supply line take into account the compressibility of the steering oil and the elasticity of hose and tubes which are essential for the hydraulic dynamics of the system.

Three main steps are used to develop the model of the supply line. At first, a tube or a hose is modeled as a single hydraulic element, and based on fluid impedance method [6], a lumped parameter model is applied to derive the impedance parameters. Then, a distributed parameter model [6] generates a dynamic relation of the inlet pressure, inlet flow rate, outlet pressure, and outlet flow rate. Finally, three transfer matrices of the three elements produce a total transfer matrix of the supply line and the dynamic feature is obtained.

Figure 3 shows a lumped parameter model of one hydraulic tube/hose element. Because strong analogies can be drawn between electrical circuits and hydraulic systems, electrical analogues are employed to analyze the hydraulic impedances.

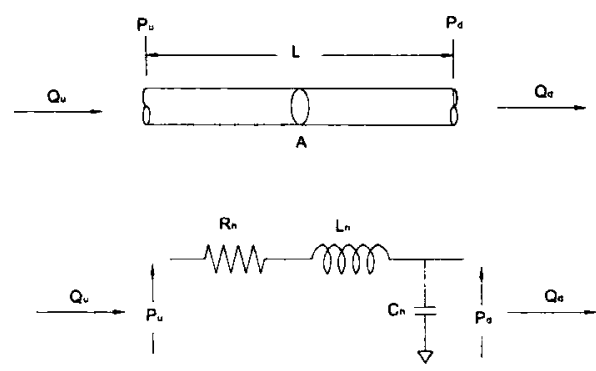

Figure 3: A lumped parameter model of pipe line.

Shown in Figure $3, Q_{u}$ and $P_{u}$ are the inlet flow rate and pressure, and the $Q_{d}$ and $P_{d}$ are the outlet ones. Fluid resistance, fluid inductance and fluid capacitance are represented by $R_{h}, L_{h}$ and $C_{h}$ respectively, and are listed in equation (3)-(5),

$$
\begin{aligned}
& R_{h}=\frac{128 \mu L}{\pi d^{4}} \\
& L_{h}=\frac{\rho L}{A} \\
& C_{h}=\frac{A L}{\beta_{e}}
\end{aligned}
$$

,where $\mu$ is the dynamic viscosity, $L$ is the length of the tube or hose, $d$ is the inner diameter of the tube or hose, $\rho$ is the density of the fluid, $A$ is the inner area of the pipe or hose, and $\beta_{e}$ is the equivalent bulk modulus. 
Using the impedance parameters, the pressure oscillation and flow ripple are investigated by distributed parameter models. Every element of the supply line is described by a transfer matrix, like Equation (6).

$$
\left[\begin{array}{c}
\bar{P}(l) \\
\bar{Q}(l)
\end{array}\right]=[T] \cdot\left[\begin{array}{c}
\bar{P}(0) \\
\bar{Q}(0)
\end{array}\right]
$$

where $\left[\begin{array}{c}\hat{P}(l) \\ \bar{Q}(l)\end{array}\right]$ and $\left[\begin{array}{c}\hat{P}(0) \\ \hat{Q}(0)\end{array}\right]$ are the outlet pressure, flow rate and the inlet pressure, flow rate respectively. The transfer matrix is

$$
\begin{aligned}
& T=\left[\begin{array}{cc}
\cosh (r l) & -Z_{c} \sinh (r l) \\
\frac{\sinh (r l)}{Z_{c}} & \cosh (r l)
\end{array}\right] \quad(7) \\
& \text {, where } \gamma=\sqrt{C_{h} j \omega\left(L_{h} j \omega+R_{h}\right)} \text { and } Z_{c}=\frac{\beta_{e} \gamma}{A \cdot j \omega} .
\end{aligned}
$$

For the supply line model, the outlet of Tube 1 is the inlet of the Hose, and the outlet of hose is the inlet of Tube 2, therefore the transfer matrix of the whole supply line is obtained by multiplying three transfer matrices of the three elements.

$$
T_{\text {sup ply }}=T_{\text {Tube-2 }} \cdot T_{\text {Hose }} \cdot T_{\text {Tube-1 }}
$$

The dynamic hydraulic responses of the supply line is shown in Equation (9),

$$
\left[\begin{array}{c}
\bar{P}_{S} \\
\bar{Q}_{S}
\end{array}\right]=\left[T_{\text {sup ply }}\right] \cdot\left[\begin{array}{l}
\bar{P}_{\text {pump }} \\
\bar{Q}_{\text {pump }}
\end{array}\right]
$$

Where $\left[\begin{array}{c}\hat{P}_{\text {pump }} \\ \hat{Q}_{\text {pump }}\end{array}\right]$ and $\left[\begin{array}{c}\hat{P}_{S} \\ \hat{Q}_{S}\end{array}\right]$ are the pressure, flow rate of the pump and the pressure, flow rate of the inlet of spool valve respectively. The output of supply line model supplies the dynamic input of rotary spool valve subsystem.

\section{ROTARY SPOOL VALVE SUBSYSTEM}

A typical rotary spool valve used in hydraulic power steering system can be modeled as a four-way open center valve which is shown in Figure 4. Classical flow orifice equations (10) describe the flow rate and pressure relations.

$$
q_{i}=C_{d} A_{i} \sqrt{\frac{2}{\rho}\left|\Delta P_{i}\right|} \quad i=1,2,3,4
$$

The supply flow rate $Q_{s}$ and load flow rate $Q_{L}$ could be calculated by the nonlinear Equations (11) and (12) [7], where the $C_{d}$ is the flow discharge coefficient, $A_{1}$ and $A_{2}$ are open areas of the orifices of the valve, $P_{s}$ and $P_{L}$ are the pressure of supply flow and the pressure

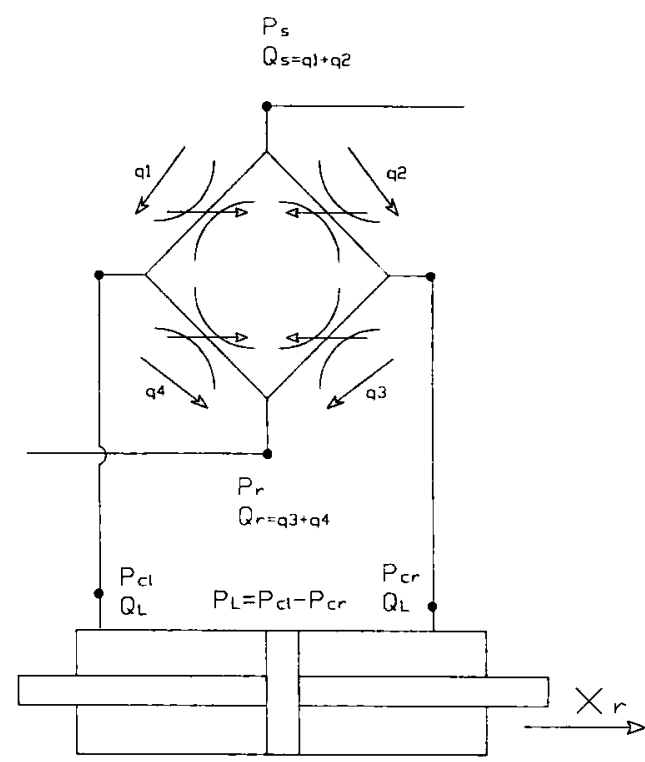

Figure 4: Schematic of Rotary Spool Valve and Hydraulic Cylinder

drop across the load, and $\rho$ is the density of the fluid.

$$
\begin{aligned}
& Q_{s}=C_{d} A_{1} \sqrt{\frac{1}{\rho}\left(P_{s}-P_{L}\right)}+C_{d} A_{2} \sqrt{\frac{1}{\rho}\left(P_{s}+P_{L}\right)} \\
& Q_{L}=C_{d} A_{1} \sqrt{\frac{1}{\rho}\left(P_{s}-P_{L}\right)}-C_{d} A_{2} \sqrt{\frac{1}{\rho}\left(P_{s}+P_{L}\right)} \\
& \dot{P}_{L}=\frac{2 \beta\left(Q_{L}-A_{P} \dot{x}_{P}\right)}{V_{\text {half }}}
\end{aligned}
$$

As with the steering oil in the supply line, the oil in the chamber of hydraulic cylinder is also considered as compressible fluid. Equation (13) is the governing equation for pressure building up, $\dot{P}_{L}$, in the chamber. In the equation, $A_{P}$ is the area of piston, $\dot{x}_{P}$ is the velocity of piston, $V_{\text {half }}$ is the half volume of the chamber and $\beta$ is the bulk modulus of the oil.

In this study, $A_{1}$ and $A_{2}$ in Equation (11) and (12) are given special attention. Unlike normal lateral spool valves and rotary spool valves, the valves used in steering systems have more complicated orifice shapes. The reason is that the valves with simple shape orifices will suddenly shut the outlets, and as a result this kind of 
valves could not satisfy the requirement of the vehicle steering feeling and may induce steering system vibration. So the edges of rotary spool slots used in steering systems are designed and manufactured with primary and secondary edges to obtain suitable hydraulic boost characteristics. Figure 5 is a top view schematic of the open area. When the spool rotates related to the sleeve, one side of orifice is opened and the other side is closed. At first, the width of $A_{2}$ of the long open edge, $W_{2}$, decreases, and after a certain angular displacement is turned, the $W_{2}$ closes totally and the short open edge, $W$, becomes the only open area. It is evident that the closing area of the orifice is nonlinear against the relative rotational degree between spool and sleeve.

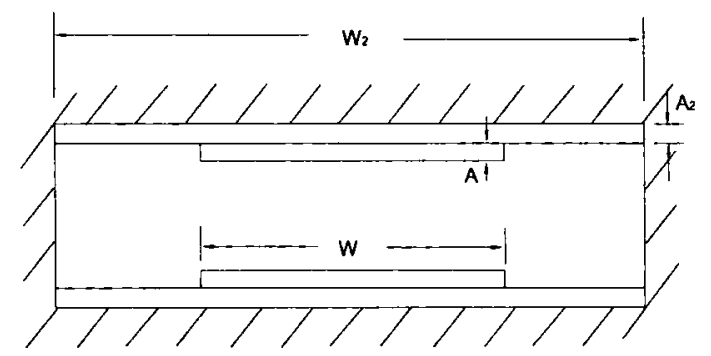

Figure 5: Schematic of Open Area of Spool Valve

Equation (14) show the nonlinearity of the closing area, where $R$ is the radius of spool, $\varphi$ is the rotational degree, and $\varphi_{k e y}$ is the certain degree which makes the long open edge closed.

$$
\text { Closing Area }= \begin{cases}A W+\left(A_{2}-R \varphi\right) W_{2} & \text { if } \varphi<=\varphi_{k e y} \\ \left(A+A_{2}-R \varphi\right) W & \text { if } \varphi>\varphi_{k e v}\end{cases}
$$

Using small computing steps, numerical calculation is conducted to solve Equations (11) to (14) which include nonlinear components and the "stiff" hydraulic elements.

\section{SIMULATION AND DISCUSSION}

\section{FREE VIBRATION ANALYSIS}

The integrated power steering system is linearised and its free vibration analysis is performed to investigate the natural frequencies and mode shapes of the mechanism subsystem.

As an example, Figure 6 shows one natural frequency and its mode shapes. In the figure, the 12 points represent the 12 elements of mechanism and the lengths of the vertical lines on the 12 points show the normalized modal coefficients at a given natural frequency of $7.32 \mathrm{~Hz}$. The symbol $\theta$ represents the angular displacement and $x$ represents the linear displacement. Corresponding to the Figure 1, point $\theta_{S W}$ represents the angular displacement of steering wheel, point $\theta_{C}$ is steering column, point $\theta_{P}$ is the pinion, point $x_{R}$ is the rack, points $\theta_{F W-L}$ and $\theta_{F W-R}$ are the left and right front wheels (road wheels) respectively, $\theta_{C P-L}$ and $\theta_{C P-R}$ are the angular displacements of the contact patches of the front tires respectively, $x_{H}$ is the hydraulic housing, $x_{V}$ is the displacement of the front half of vehicle and $x_{F W-L}, x_{F W-R}$ are the lateral displacement of the two front wheels.

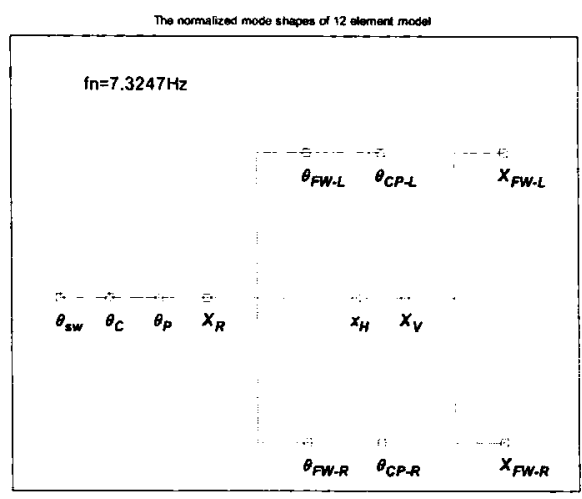

Figure 6: Natural Frequency and Mode Shapes

In Figure 6, the values of mode shapes of the steering wheel and steering column are the largest, and the value of pinion's mode shape is also considerable. The normalized modal coefficients of displacements $(x)$ are too small to be shown in this figure. It can be noticed that the steering wheel, steering column and pinion are the main vibration components, or called dominant components, in this natural frequency $(7.32 \mathrm{~Hz})$, and they affect this natural frequency much greater than other components.

Table 1 lists 11 natural frequencies of the mechanism subsystem, as well as the responding dominant vibration components in each natural frequency. The $0 \mathrm{~Hz}$ rigid body motion generated by the free vibration analysis is not listed in the table.

It shows the pinion affects several natural frequencies because of its small inertia. The No. 11 natural frequency $(718.45 \mathrm{~Hz})$ is studied as an example to investigate sensitivity of inertia of pinion to the mechanism subsystem. In Figure 7 , the $x$ axis is the percentage of changes of the inertia of pinion from a benchmark valve and the $y$ axis is the percentage of 
changes of the No.11 natural frequency, the highest natural frequency of the mechanism subsystem. It is shown that if the inertia of pinion increases $20 \%$, the natural frequency decreases $15 \%$, and if the inertia decrease $20 \%$, the natural frequency increase $22 \%$. This means the reduction of the inertia of pinion affects the natural frequency more that the increase of it does.

\begin{tabular}{|c|c|l|}
\hline No. & $\begin{array}{c}\text { Natural } \\
\text { Frequency } \\
(\mathrm{Hz})\end{array}$ & Dominant Components \\
\hline 1 & 2.41 & $\begin{array}{l}\text { Hosing, vehicle body and lateral } \\
\text { movement of two wheels }\end{array}$ \\
\hline 2 & 4.93 & Two tires \\
\hline 3 & 6.99 & Two wheels and two tires \\
\hline 4 & 7.32 & $\begin{array}{l}\text { Steering wheel, column and partly } \\
\text { because of pinion }\end{array}$ \\
\hline 5 & 22.13 & Hydraulic cylinder \\
\hline 6 & 47.88 & Lateral vibration of two wheels \\
\hline 7 & 48.85 & Lateral vibration wheels \\
\hline 8 & 78.60 & Two tires \\
\hline 9 & 82.78 & Pinion and steering column \\
\hline 10 & 126.77 & Pinion and steering column \\
\hline 11 & 718.45 & Pinion \\
\hline
\end{tabular}

Table 1: Mechanism Subsystem Natural Frequencies and Dominant Components

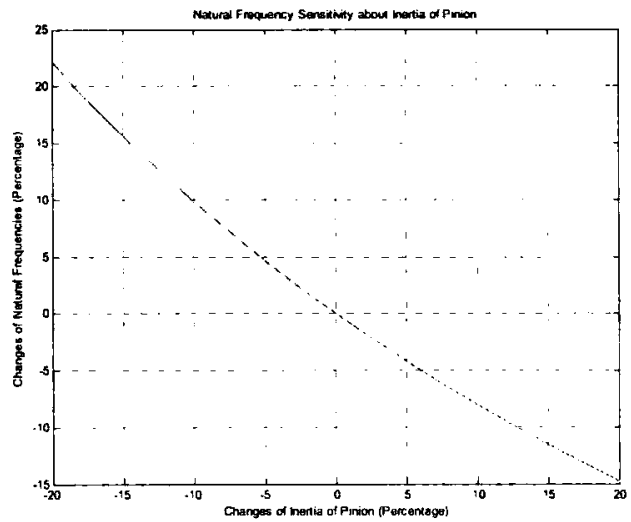

Figure 7: Effect of Inertia of Pinion on Natural Frequency

\section{NUMERICAL ANALYSIS IN TIME DOMAIN}

Based on the previous study, three subsystems, including the mechanism, supply line and rotary spool valve, are integrated into a highly nonlinear hydraulic power steering system model. Runge-Kutta method is used in the numerical calculation to analyze the model in the time domain. Steering at parking speed is demonstrated here as an example because the steering shudder is most likely to occur in this situation.

Figure 8 shows a typical steering system's response in the first 0.5 second when the vehicle is at park speed. At time 0 , the steering system is neutral, from time 0 a ramp input torque is applied on the steering wheel. The top left plot is the angular displacement of the steering wheel and the pinion, the top right plot shows the angular displacement of the front wheels and tires, the bottom left plot shows the twist angle of the torsional bar and the boost force in the hydraulic chamber is shown in the bottom right plot.
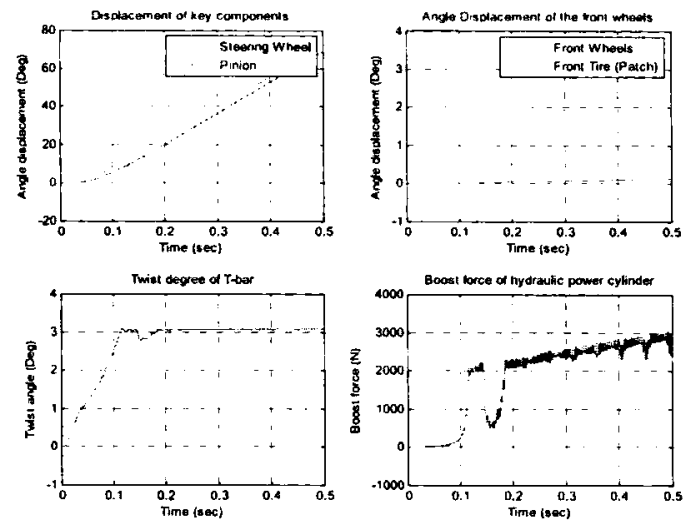

Figure 8: System Responses Using Standard Parameters

It is found that the length of short open edge ( $W$ in Figure 5) of the spool valve has important effects on the system. If all other parameters of the system are kept as constants and $W$ changes even within a small valve, the response of the system changes significantly.
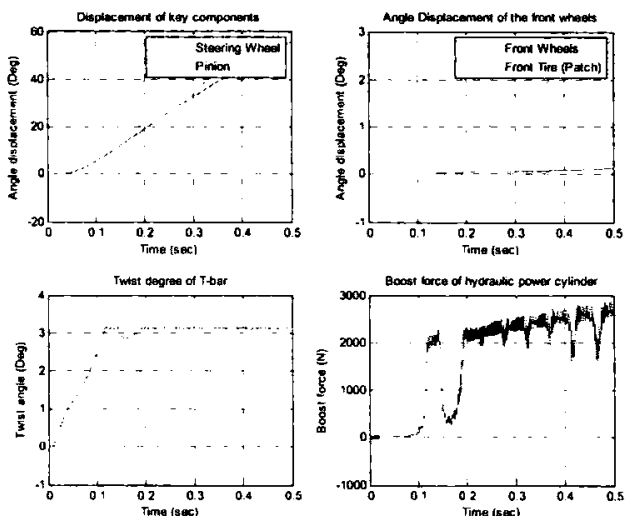

Figure 9: System Responses Using longer W

As an example, Figure 9 shows the system responses after $W$ becomes $4 \mathrm{~mm}$ longer than the benchmark value. Under the same input, the angular displacement 
of steering wheel decreases $20 \%$. The amplitude of vibration of the hydraulic boost force increases a lot though the absolute value of it does not change much.

By comparing the responses using various parameters, it is found that when $\mathrm{WN}_{2}$ (Refer to Figure 5) is about $60 \%$ the vibration of the boost force is least, and when $W$ deviates from this value the vibration of the boost force increases. Furthermore, the system becomes unstable if $W / W_{2}>95 \%$ or $W / W_{2}<10 \%$.

Besides the length of short open edge of spool valve, the pressure oscillation and flow rate ripple from pump also affect the dynamics of the system. It shows that if the pressure oscillation from pump increases from the $1 \%$ of the pump pressure to $5 \%$ of the pump pressure, the boost force vibration amplitude increases from about $4 \%$ of the boost force to $8 \%$. And, if other parameters are constants and the flow rate ripple raises from $1 \%$ of the flow rate of pump to $5 \%$, the boost force vibration will increase from $4 \%$ of the value of boost force to $20 \%$. It shows the steering system is more sensitive to flow rate ripple of pump than the pressure oscillation of pump.

\section{CONCLUSION}

A highly nonlinear hydraulic power steering system model has been developed and effects of the key parameters for the dynamics of the system are investigated. It is found that the length of short open edge $W$ and the flow rate ripple from pump affect the dynamics of the system greatly. Also the pressure oscillation significantly contributes to the vibration of the system. The developed analytical method could assist the design and analysis of hydraulic power steering systems.

\section{REFERENCES}

1. Tom Wang, "Hydraulic Power Steering System Design and Optimization Simulation", SAE Technical Paper Series 2001-01-0479, 2001

2. Gary R. Ferries and R. Larry Arbanas, "Control/Structure Interaction in Hydraulic Power Steering Systems", Proceedings of the American Control Conference Albuquerque, New Mexico, USA, 1997, Page 1146-1151

3. Tsugiharu Matsunaga, Toshiyuki Tanaka and Shinji Nishimura, "Analysis of Self-excited Vibration in Hydraulic Power Steering System: Prevention against Vibration by Supply Line", SAE Technical Paper Series 2001-01-0488, 2001

4. R S Sharp and R Granger, "On Car Steering Torque at Parking Speed", Proceedings of the Institution of Mechanical Engineers Vol. 217 Part D: Journal of Automobile Engineering, 2003, Page 87-96

5. Qatu, M., D. Llewellyn, and R. Edwards, "Correlation of Hydraulic Circuit Dynamic Simulation and Vehicle" SAE Technical Paper Series 2000-01-0811, 2000.
6. D. McCloy and H. R. Martin, Control of fluid power: analysis and design, $2^{\text {nd }}$ (revised) Edition. Chichester, England: Ellis Horwood Limited, 1980, pp.236-240.

7. H. E. Merritt, Hydraulic Control Systems. New York, NY: John Wiley and Sons, 1967 